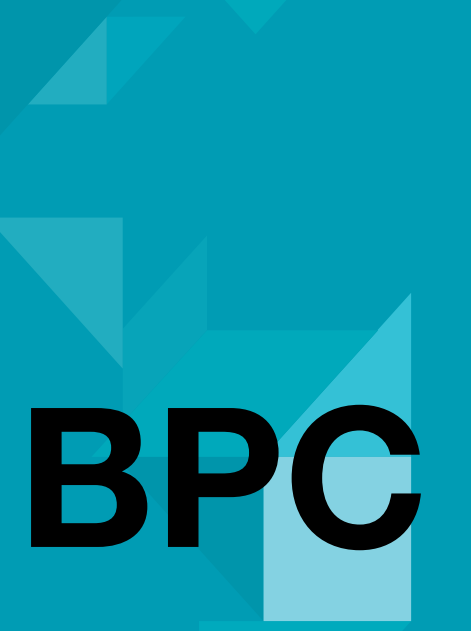

\title{
A Caminho da
}

\section{Transição Energética?}

O papel dos atores e interesses privados

em meio à governança policêntrica do clima

Beatriz Rodrigues Bessa Mattos
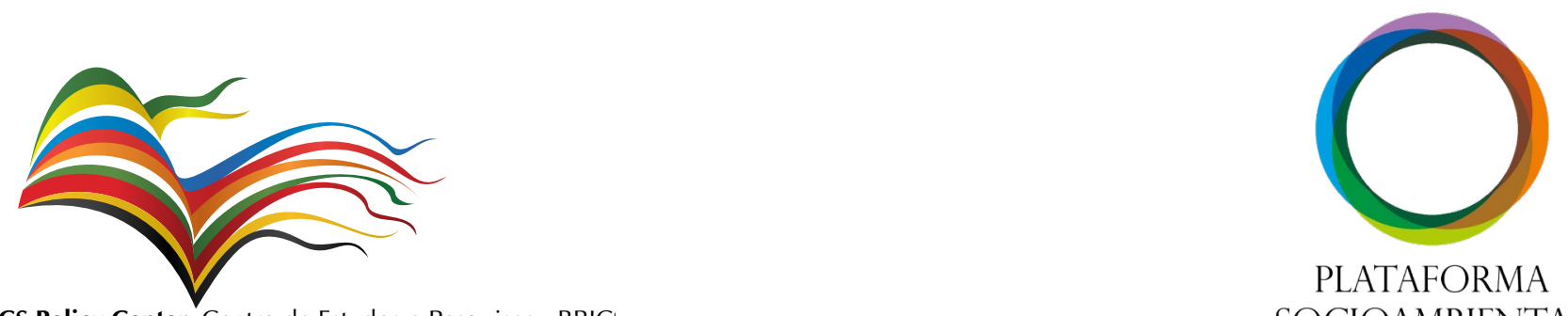


\title{
Sobre o BRICS Policy Center
}

O BRICS Policy Center é dedicado ao estudo dos países BRICS (Brasil, Rússia, Índia, China e África do Sul) e demais potências médias, e é administrado pelo Instituto de Relações Internacionais da PUC-Rio (IRI), em colaboração com o Instituto Pereira Passos (IPP).

Todos os papers têm sua publicação condicionada a pareceres externos. As opiniões aqui expressas são de inteira responsabilidade do(a)(s) autor (a) (es) (as), não refletindo, necessariamente, a posição das instituições envolvidas.

\section{BRICS Policy Center}

Rua Dona Mariana, 63 - Botafogo

Rio de Janeiro / RJ / Brasil

Telefone: +55 21 2535-0447

CEP: 22280-020

www.bricspolicycenter.org

bpc@bricspolicycenter.org

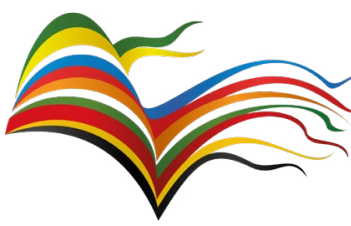

BRICS

Policy Center

Centro de Estudos

e Pesquisas BRICS

\section{Plataforma Socioambiental}

\author{
COORDENADOR \\ Paulo Esteves \\ PESQUISADORAS \\ Maureen Santos \\ Beatriz Mattos \\ Carolina Alves \\ Carolina Medina \\ ESTAGIÁRIOS \\ Anayet Bolea \\ Emily Perez \\ Zaira Apolinario \\ Michelangelo Vaira
}

\section{BPC Team}

DIRETOR

Paulo Esteves

COORDENADORA ADMINISTRATIVA

Lia Frota e Lopes

ASSISTENTE ADMINISTRATIVA

Luana Freitas

GERENTE DE PROJETOS E COMUNICAÇÃO

Thalyta Ferraz

DIAGRAMAÇÃO E DESIGN

Vinicius Kede
BPC Papers V. 6 N. 02 - Maio - Agosto/2019. Rio de Janeiro. PUC. BRICS Policy Center ISSN: 2357-7681

$24 p ; 29,7 \mathrm{~cm}$

1. Governança Policêntrica. 2. Acordo de Paris.

3. Transição Energética. 4. Mudança Climática 


\section{Sumário}

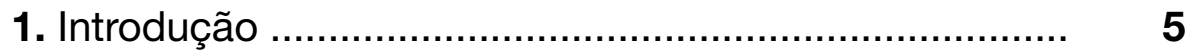

2. O debate sobre Governança Policêntrica no regime climático

3. Energia e Clima: a atuação dos atores privados em meio à governança de clima

4. IRENA Coalition for Action

5. SEforALL

6. Iniciativas na Plataforma NAZCA

7. Considerações Finais

8. Referências Bibliográficas

Anexo 1: Lista de Atores Privados Membros da IRENA Coalition for Action 


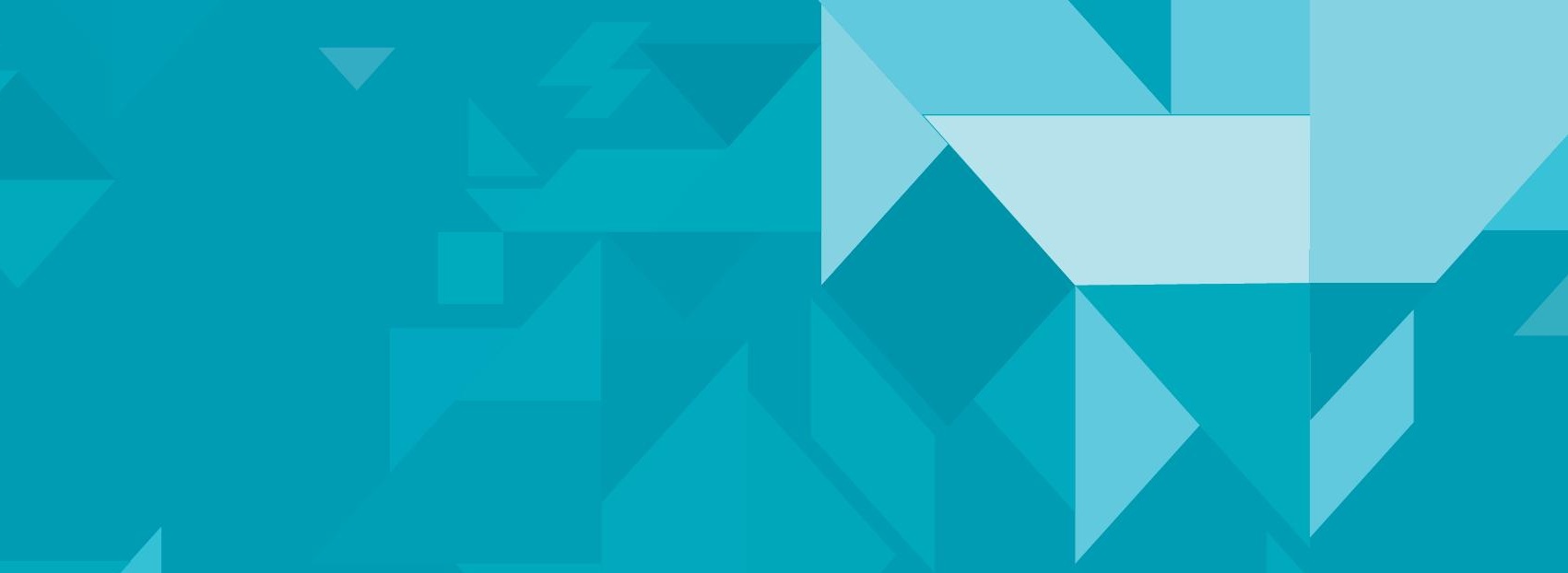

\section{Sumário Executivo}

Este paper tem como principal objetivo analisar o papel dos atores privados do setor de energia em meio ao novo modelo de governança de clima, também denominado como governança policêntrica. A estrutura desta publicação é dividida em quatro partes. A primeira oferece uma breve contextualização acerca das transformações sofridas no âmbito dos regimes ambientais, de forma a possibilitar a participação crescente de atores não-estatais na implementação dos acordos internacionais. A segunda parte analisa duas plataformas de cooperação energética que desempenham papeis relevantes em meio às Conferências das Partes (COPs) da Convenção Quadro das Nações Unidas de Mudança do Clima (UNFCCC, sigla em inglês). São essas: o Coalition For Action, mediado pela International Renewable Energy Agency (IRENA), e o Sustainable Energy for All (SEforALL). Ambas iniciativas são plataformas globais - compostas por membros governamentais, privados e não governamentais - que defendem a transição para as fontes de energia renováveis e mostram-se discursivamente comprometidas com os objetivos do Acordo de Paris e da Agenda 2030. A terceira parte realiza um mapeamento do perfil dos stakeholders privados pertencentes a esses dois grupos, tendo em vista a análise de seus principais interesses - ambientais, econômicos e sociais - tais quais declarados em seus websites e documentos oficiais. Por fim, a quarta seção desta publicação aponta para as iniciativas registradas pelos atores aqui abordados na chamada Non-State Actor Zone for Climate Action (NAZCA), uma plataforma virtual gerenciada pelo Secretariado da UNFCCC, que visa acelerar as contribuições de atores não-estatais para o alcance das metas do regime do clima.

\section{Palavras Chave}

Governança Policêntrica; Acordo de Paris; Transição Energética; Mudança Climática 


\section{A Caminho da Transição Energética? \\ $\mathrm{O}$ papel dos atores e interesses privados em meio à governança policêntrica do clima}

Beatriz Rodrigues Bessa Mattos

\section{Introdução}

A transição para uma matriz energética global mais sustentável representa um pré-requisito fundamental para o sucesso de dois marcos internacionais vigentes. Por um lado, no âmbito do regime internacional do clima, o alcance do objetivo do Acordo de Paris - de garantir que o aumento da temperatura do planeta não exceda $2^{\circ} \mathrm{C}$, com esforços para limitá-la a $1.5^{\circ} \mathrm{C}$, em relação aos níveis pré-industriais - mostra-se inatingível na ausência de uma transformação profunda no que diz respeito às fontes energéticas. Por outro, a Agenda 2030, por meio do sétimo Objetivo de Desenvolvimento Sustentável (ODS), também ressalta a necessidade de garantir o acesso à energia barata, confiável, sustentável e renovável para todos.

Tanto o Acordo de Paris quanto a Agenda 2030 são frutos de negociações que ocorrem em meio aos foros multilaterais. Tais espaços políticos, tradicionalmente limitados à participação de atores estatais, vêm sofrendo mudanças significativas nos últimos anos. Nesse sentido, alguns autores vêm empregando o conceito de governança policêntrica para caracterizar o emaranhado de atores e processos inseridos em meio à essas negociações. (Ostrom, 2010; Jordan et al., 2015; Inoue, 2016) Desafiando o modelo tradicional e estadocêntrico de regimes, a governança policêntrica abre espaço para a participação dos chamados non-party stakeholders (Bäckstrand; Kuyper, 2017) nos processos de tomada de decisão e de implementação e vem sendo apontada (Benner et al, 2003; Streck, 2004) como capaz de reduzir o déficit democrático, promover maior transparência e a elevar a eficiência dos regimes internacionais. 


\section{Figura 1: Algumas Categorias de non-party stakeholders que compõem a governança de clima. Fonte: elaboração própria.}

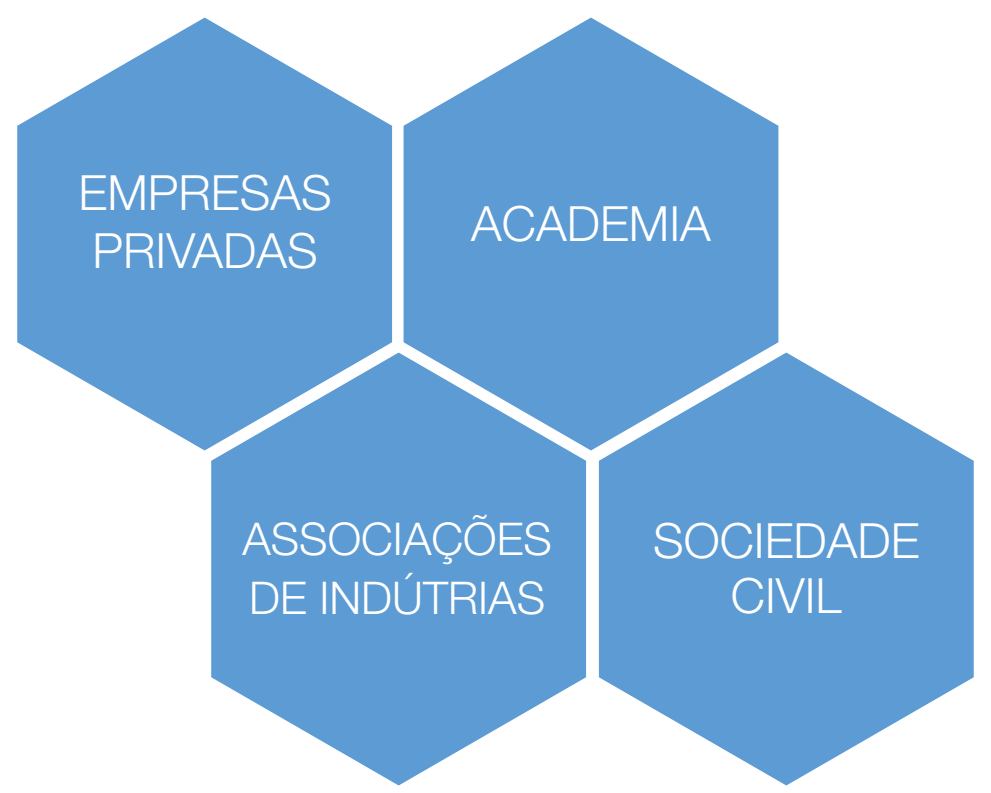

Aliado à essa conjuntura, a Plataforma Socioambiental do BRICS Policy Center (BPC), em parceria com o Instituto Clima e Sociedade (ICS), desenvolveu o projeto de Mapeamento da Governança Policêntrica do Clima, que teve por objetivo analisar o papel dos atores privados do setor de energia em meio a este novo modelo de governança. Tal mapeamento deu origem a um Diagrama ${ }^{1}$, em que são apresentadas as principais coalizões de energia que atuam em meio ao regime climático, bem como ao presente paper. Foram promovidos ainda alguns webinars ${ }^{2}$ em parceria com o Institute for Advanced Sustaintability Studies (IASS), da Alemanha, cujos debates sobre o status atual da governança de clima colaboraram para as reflexões apresentadas neste paper.

A estrutura desta publicação é dividida em quatro partes. A primeira, tendo como ponto de partida o conceito de governança policêntrica, oferece uma breve contextualização acerca das transformações sofridas no âmbito dos regimes ambientais, de forma a possibilitar a participação crescente de atores não-estatais na implementação dos acordos internacionais. A segunda parte analisa duas plataformas de cooperação energética que desempenham papeis relevantes em meio às Conferências das Partes (COPs) da Convenção Quadro das Nações Unidas de Mudança do Clima (UNFCCC, sigla em inglês). São essas: o Coalition For Action, mediado pela International Renewable Energy Agency (IRENA), e o Sustainable Energy for All (SEforALL). Ambas iniciativas são plataformas globais - compostas por membros governamentais, privados e não governamentais - que defendem a transição para as fontes de energia renováveis e mostram-se discursivamente comprometidas com os objetivos do Acordo de Paris e da Agenda 2030. Vale ressaltar que o mapeamento foi realizado com base apenas nos atores privados que compõem essas duas coalizões, que contemplam em suas plataformas empresas cuja atuação exemplifica de forma clara as interseções entre os setores de clima e de energia. Neste sentido, a terceira parte deste PB realiza um mapeamento do perfil dos stakeholders privados ${ }^{3}$ perten-

(1) Disponível no website do BRICS Policy Center: http://www.bricspolicycenter.org/

(2) Agradecemos em especial à Cristina Inoue por suas importantes contribuições acerca da governança policêntrica.

(3) O mapeamento das coalizões e empresas de energia na governança policêntrica do clima foi produzido por Carolina Alves, Beatriz Mattos e Maureen Santos, da equipe da Plataforma Socioambiental 
centes a esses dois grupos, tendo em vista a análise de seus principais interesses - ambientais, econômicos e sociais - tais quais declarados em seus websites e documentos oficiais. Por fim, a quarta seção deste PB aponta para as iniciativas registradas pelos atores aqui abordados na chamada Non-State Actor Zone for Climate Action (NAZCA) ${ }^{4}$, uma plataforma virtual gerenciada pelo Secretariado da UNFCCC, que visa acelerar as contribuições de atores não-estatais para o alcance das metas do regime do clima.

\section{Odebate sobre GovernançaPolicêntricano regime climático}

Elinor Ostrom (2010) foi uma das primeiras autoras a defender a transformação da arquitetura dos regimes ambientais. Influenciada pelos estudos de Vincent Ostrom, Charles Tiebout e Robert Warrent (1961), que apontavam que a manutenção da oposição clássica entre o Estado e o setor privado não seria a forma mais eficaz de se promover bens públicos, Ostrom argumenta que a resposta aos problemas globais deve abarcar atores dos mais variados níveis. Para a autora, as soluções globais, tais quais negociadas tradicionalmente por Estados no âmbito dos foros multilaterais, possuem uma série de fragilidades. Entre essas, as dificuldades de implementação em nível local e o déficit democrático, que faria com que as necessidades das populações mais afetadas pelos problemas socioambientais não fossem satisfatoriamente endereçadas. Ostrom propõe, assim, um regime de governança policêntrica, caracterizado pela maior participação de atores não-estatais e pela existência de diversos centros de decisão formalmente independentes, como uma alternativa ao modelo estadocêntrico de governança. (Inoue, 2016: 111)

Pode-se dizer que o atual modelo de governança do clima - capitaneado pela UNFCCC, que tem como instrumento vinculante o Acordo de Paris - vem se aproximando da proposta de governança policêntrica de Ostrom. (Jordan et al., 2018) Tal modelo começou a ser delineado ainda no início da década de 1990, quando foi possível notar transformações na relação entre os atores não-estatais e a ONU. (Mert, 2015) Desde a Conferência das Nações Unidas sobre Meio Ambiente e Desenvolvimento (UNCED, sigla em inglês), também conhecida como Rio92, nota-se uma maior participação de organizações não-governamentais, representantes da comunidade científica e empresas privadas em meio aos foros de negociação. A importância inédita conferida a esses atores refletiu-se, inclusive, no texto da Agenda $21^{5}$, que destaca a necessidade de garantir a participação de grupos vulneráveis (comunidades tradicionais, povos indígenas, mulheres) e de outros atores não-estatais (como multinacionais e organizações não-governamentais), no processo de tomada de decisão visando assegurar o desenvolvimento sustentável. (Biermann et al, 2007)

Dez anos depois, durante a Cúpula Mundial sobre Desenvolvimento Sustentável (WSSD, sigla em inglês) realizada em Joanesburgo, uma transformação ainda mais significativa seria verificada. Mediante ao fracasso em se alcançar um acordo efetivo e vinculante entre os Estados (Type 1 outcome), as chamadas Parcerias de Tipo 2 ou Multistakeholder Partnerships foram celebradas como o principal fruto da cúpula. (Mert, 2015) Essas iniciativas dizem respeito a um processo de colaboração voluntária entre atores públicos e privados, que teriam como objetivo auxiliar no alcance das metas socioambientais, tais quais negociadas entre os Estados. (Mert, 2015)

do Brics Policy Center, a partir do projeto apoiado pelo Instituto Clima e Sociedade e está disponível em: <www.bricspolicycenter.org $>$

(4) Website Oficial da NAZCA. Disponível em: <http://climateaction.unfccc.int/views/map.html> Acesso em: 8 de maio de 2019.

(5) Vale notar que, além da Agenda 21, a Conferência do Rio também resultou na inauguração da Convenção Quadro das Nações Unidas de Mudanças Climáticas (UNFCCC, sigla em inglês) e na Convenção de Diversidade Biológica (CDB). 
Tais parcerias passaram a ser justificadas por narrativas que enfatizavam os potenciais ganhos mútuos resultantes de uma divisão de trabalho entre atores estatais e privados. Em 2009, mais uma iniciativa foi tomada nesse sentido, quando durante a Conferência das Partes da UNFCCC, em Copenhague (COP 15), a abordagem top-down e estadocêntrica representada pelo Protocolo de Quioto foi substituída por uma arquitetura descentralizada e flexível, que permitiu que as metas globais de redução das emissões fossem substituídas por comprometimentos voluntários. (Victor, 2011; Bäckstrand; Kuyper, 2017)

Assim, se a Rio92 marca o momento de maior participação de atores não-estatais em meio aos foros multilaterais ambientais ${ }^{6}$, a Cúpula de Johanesburgo, a COP 15 e, mais recentemente, o Acordo de Paris, os insere como peças fundamentais para a implementação das metas acordadas. (Mert, 2015: 290) Como resultado, nota-se um novo modelo de governança que mescla interesses de atores privados e públicos e que conjuga diferentes racionalidades, se aproximando, portanto, do que alguns autores denominam como governança policêntrica. (Bäckstrand et al., 2010; Bäckstrand et al., 2017)

No que diz respeito mais especificamente à governança de clima, nota-se uma maior participação de atores privados, em especial, no processo de implementação das metas acordadas. Tendo em visa a importância crescente conferida ao setor de energia para a redução das emissões de gases do efeito estufa e, consequentemente, para o combate à mudança do clima, a análise sobre quem são os atores inseridos em meio a esse novo modelo de governança, quais são seus principais interesses e como suas iniciativas dialogam com os objetivos fundamentais do regime torna-se premente.

As inciativas conjuntas entre atores públicos e privados, tais quais as defendidas pelos autores da economia política citados por Ostrom, já se verificam há muito no âmbito nacional. Contudo, tratam-se de um fenômeno mais recente no que diz respeito a promoção de bens comuns globais, como o Acordo de Paris e os ODS. Aysem Mert (2015) ressalta que essas parcerias globais apresentam algumas diferenças quando comparadas aquelas que ocorrem domesticamente. A autora argumenta que tais ações carecem de um mecanismo público de monitoramento e accountability e que, apesar de contarem com grande número de stakeholders, nem sempre é possível observar a presença dos indivíduos mais afetados pelos problemas que se busca combater - no caso em questão, as mudanças climáticas - e pelas políticas discutidas como soluções para esses problemas. Outro ponto ressaltado diz respeito ao caráter puramente voluntário de tais parcerias, o que faz com que os atores envolvidos frequentemente declarem objetivos e políticas excessivamente vagos. (Mert, 2015: 290)

O Acordo de Paris, aprovado pelos Estados Parte da UNFCCC em 2015, segue essa mesma racionalidade. Diferentemente de seu antecessor, o Protocolo de Quioto, Paris não estabelece uma meta de corte de emissões para os Estados signatários. Empregando um modelo bottom-up, o Acordo abre espaço para que as Partes estabeleçam voluntariamente suas metas de redução de emissões de gases de efeito estufa, exigindo apenas que essas sejam revistas a cada cinco anos, com o objetivo de torná-las mais ambiciosas. As Contribuições Nacionalmente Determinadas (NDCs) representam, logo, o principal instrumento do Acordo, lançando bases para os esforços de redução das emissões e, consequentemente, para o alcance do objetivo fundamental do regime de clima: a limitação da temperatura do planeta.

(6) Vale notar que a Rio92 foi parte da chamada década social das Nações Unidas, momento em que foram realizadas diversas conferências multilaterais, voltadas aos mais variados temas, com esse mesmo formato mais participativo. 
Paris não apenas reconhece, como também incentiva a contribuição de atores não-estatais, em especial atores privados, na implementação e financiamento para a implementação das NDCs das Partes. O alcance de suas metas mostra-se, portanto, condicionado ao comprometimento não apenas dos Estados signatários, como também dos non-party stakeholders pertencentes aos mais variados níveis, tal qual defendido por Ostrom. Por exemplo, no artigo 6 do Acordo de Paris, que se refere aos mecanismos de mercado e não mercado, estão previstas nos parágrafos 4.b e 8.b iniciativas com a participação do setor privado voltadas à mitigação de gases de efeito estufa e à implementação das NDCs, respectivamente. (UNFCCC, 2015). Além disso, na decisão da COP 21 (CP.21), os non-party stakeholders são citados em onze partes do texto, sendo o Capítulo V inteiramente dedicado à contribuição desses atores.

Os documentos oficiais da UNFCCC parecem, assim, corroborar com a percepção de que os atores não-estatais vêm se mostrando cada vez mais relevantes em meio à governança do clima. (Bäckstrand et al., 2017: 762; Jordan et al., 2018)

Assim, se por um lado, o atual modelo de governança climática mostra-se mais abrangente, permitindo a maior participação de múltiplos stakeholders, por outro, nota-se preocupações acerca da permeabilidade do regime a interesses e pressões de uma ampla gama de atores, que passam a influenciar em suas regras e procedimentos. Nesse sentido, observa-se uma tendência crescente à desregulamentação seletiva, a esquemas voluntários e à busca por soluções com base em mecanismos de mercado. (Mert, 2013: 226) Iniciativas como a criação de instrumentos para comercialização de emissões de carbono e a promoção de novas técnicas de geoengenharia passam a ser apresentadas como possíveis meios para o alcance das metas climáticas, de modo a beneficiar atores do setor privado, com pouco ou quase nenhum diálogo com organizações da sociedade civil, povos indígenas e comunidades locais, tal qual estabelecido pela Agenda 21 e a Convenção 169 da OIT7.

Cientes dessas dificuldades, alguns autores (Abbott; Snidal, 2010) apontam para a necessidade de se eleger um ator capaz de orquestrar esse novo modelo de governança descentralizado, no sentido de promover e distribuir co-benefícios entre os agentes participantes, monitorar ações e garantir o alcance das metas. Nesse sentido, o Secretariado da UNFCCC pode ser apontado como o ator responsável por orquestrar as ações voluntárias de intermediários - sejam essas empresas, organizações não governamentais, povos e comunidades locais e iniciativas transnacionais - para auxiliar no alcance das metas climáticas. Tal função fica evidente em iniciativas como a NAZCA, uma plataforma digital, operada pelo Secretariado, que tem como objetivo contabilizar as ações de atores não-estatais e subnacionais com vistas a preencher o gap de corte de emissões globais. (Bäckstrand; Kuyper, 2017: 770) Nas seções finais deste estudo, serão apresentadas considerações sobre as principais funções do NAZCA, o teor das iniciativas registradas por atores privados do setor de energia nesta plataforma, bem como sobre as fragilidades e desafios enfrentados por esta iniciativa.

(7) Recentemente, foi aprovada na UNFCCC a Plataforma dos povos indígenas e comunidades locais, que cria um espaço permanente de interlocução com esses setores, e cujo conselho é paritário entre estados e organizações representativas desses povos. 


\section{Energia e Clima: a atuação dos atores privados em meio à governança de clima}

Tendo em vista a breve contextualização aqui apresentada, as próximas seções deste PB voltam-se à análise dos interesses declarados e as ações dos atores privados que compõem duas grandes coalizões de energia que operam em meio às negociações. Apesar de as iniciativas aqui abordadas - IRENA Coalition for Action e SEforALL - contarem com membros diversos ${ }^{8}$, que não se reduzem à iniciativa privada, esse paper não incluirá em seu recorte analítico organizações não governamentais que compõem essas coalizões. A análise aqui apresentada recairá sobre os stakeholders enquadrados como atores privados, bem como sobre seus interesses declarados em seus websites e documentos oficiais ${ }^{9}$. Posteriormente, serão brevemente analisadas as iniciativas registradas pelos membros dessas duas coalizões na plataforma NAZCA, que atualmente contabiliza 2.431 iniciativas apresentadas por empresas privadas para contribuir com o alcance das metas do clima.

Tendo em vista a sua natureza privada, é esperado que os atores aqui analisados guiem-se fundamentalmente por incentivos econômicos, que podem ou não se mostrar convergentes com o objetivo de redução das emissões. Contudo, a análise qualitativa dos interesses secundários declarados por essas empresas, no que diz respeito a objetivos socioambientais e de segurança energética, conjugada ao levantamento das iniciativas registradas por essas mesmas empresas na plataforma NAZCA pode oferecer um panorama interessante a respeito do nível de comprometimento e ambição desses atores, que dispõe de participação e agência cada vez mais amplas em meio ao regime do clima.

\section{IRENA Coalition for Action}

Lançada em 2014, o Coalition for Action configurase como coalizão capitaneada pelo IRENA, cujo enfoque fundamental é a aceleração da transição energética. Enquanto o IRENA caracterizase como uma agência intergovernamental, que conta atualmente com 159 Estados membros - 24 Estados encontram-se em processo de adesão, entre esses o Brasil -, a Coalition for Action é uma coalizão mais diversa, composta por 84 stakeholders. (IRENA, 2018) Entre esses, verificamse empresas privadas, associações de

(8) O IRENA é composto também por outros atores não estatais, com especial destaque para organizações da sociedade civil como a Climate Action Network (CAN), o Greenpeace International e o WRI, que se mostram bastante ativos no que diz respeito ao debate climático e a participação nos processos oficiais.

(9) A listagem dos atores privados de cada uma dessas coalizões, bem como com os websites oficiais e documentos consultados para a realização do mapeamento foram incluídos nas seções finais deste paper.

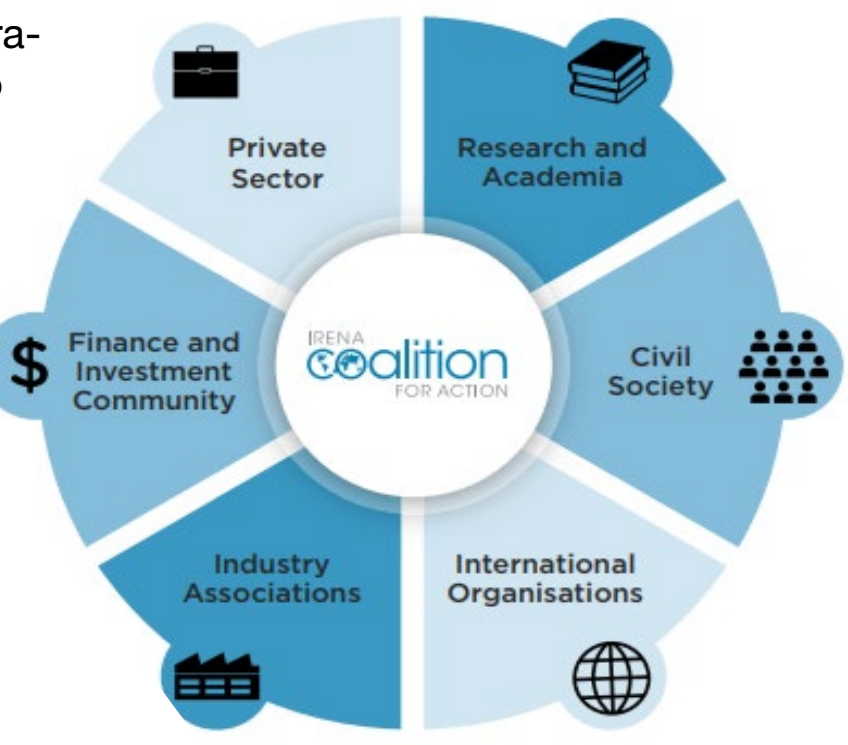

Figura 2: Categorias de Membros do IRENA Coalition For Action. Fonte: IRENA, 2018. 
indústrias, organizações intergovernamentais, entidades financeiras, institutos de pesquisa e representantes da sociedade civil. A coalizão destina-se a identificar e discutir tendências no setor de energias renováveis, bem como compartilhar conhecimento e práticas voltadas ao processo de transição energética, em especial no que diz respeito a questões como novas tecnologias, dinâmicas de mercado e estratégias políticas ${ }^{10}$. A coalizão se apresenta, assim, como uma plataforma destinada a potencializar a coordenação política entre seus membros, a ampliar a comunicação acerca das energias renováveis e a promover o engajamento com governos e organizações internacionais.

A Coalition for Action não possui, portanto, um interesse direto na redução das emissões objetivo fundamental do regime do clima - mas sim nos meios empregados para alcançar tal meta, que seria então a aceleração do processo de transição energética. Tal anseio reflete-se igualmente nos interesses de seus membros privados. Entre seus 84 membros, 20 classificam-se como empresas privadas, o que se configura como cerca de $24 \%$ dos membros totais. Além dos interesses econômicos óbvios em relação à expansão de mercado e de lucros, bem como ao desenvolvimento de novas tecnologias, as empresas que fazem parte da coalizão também manifestam interesses em outros âmbitos, como o social, o ambiental e de segurança.

A análise qualitativa dos interesses declarados nos websites e documentos oficiais das empresas privadas que fazem parte do Coalition for Action revelou que entre os interesses ambientais frequentemente declarados estão: proteger a biodiversidade, otimizar o uso e o gerenciamento dos recursos hídricos, prevenir a poluição, combater a mudança do clima e preservar os recursos do planeta. Foram identificados como interesses na arena social: aliviar a pobreza, promover o desenvolvimento, garantir os direitos humanos em meio às cadeias produtivas, reduzir a desigualdade e criar empregos. Por fim, algumas empresas ressaltam ainda interesses no âmbito da segurança, como reduzir a dependência de países desenvolvidos e em desenvolvimento de combustíveis fósseis e de energia nuclear e garantir a segurança energética. Entre as 20 empresas analisadas, apenas 8 declararam interesse em questões diretamente relacionadas ao combate às mudanças climáticas, enquanto 2 (ACCIONA e Qway Energy) declararam explicitamente que suas ações contribuem para o alcance das metas do Acordo de Paris ${ }^{11}$.

\section{Quadro 1: Membros e Interesses do IRENA Colation for Action}

IRENA Coalition For Action

Total

Atores Privados

Atores Privados com Interesses na área ambiental

Atores Privados com Interesses no combate as mudanças climáticas

Atores Privados discursivamente comprometidos com o Acordo de Paris

(10) Website Oficial do IRENA. Disponível em: < http://coalition.irena.org/-/media/Files/IRENA/Coalition-for-Action/IRENA-Coalition-for-Action June-2018 v1.pdf > Acesso em: 20 de abril 2019.

(11) A lista de websites e documentos oficiais consultados para a realização do mapeamento dos interesses das empresas se encontra nas páginas finais deste paper. 


\section{SEforALL}

A coalizão Sustainable Energy For All apresenta-se como uma organização internacional cujo principal escopo é auxiliar governos, sociedade civil e atores privados a promover rápidas mudanças para alcançar os objetivos do Acordo de Paris e o ODS 7 da Agenda 2030. Lançada em 2011 pelo ex-Secretário Geral da Organização das Nações Unidas, Ban Ki-moon, a coalizão destaca os nexos existentes entre energia e problemas socioambientais como a pobreza e as mudanças climáticas e enumera como seus principais objetivos garantir acesso universal à energia; dobrar a eficiência energética global e dobrar a contribuição das energias renováveis na matriz energética do planeta. Para isso, a organização busca incentivar parcerias e facilitar o financiamento de projetos no setor ${ }^{12}$. A SEforALL também é responsável pela publicação de uma série de relatórios, chamada Energizing Finance, contendo dados atualizados acerca do financiamento anual global em energia.

A organização conta com três categorias de parceiros: os chamados Delivery Partners; os Proud Partners e, finalmente, os Funding Partners.(SEforALL, 2016) Os Delivery Partners são atores comprometidos com a ampliação do acesso à energia, o aumento da eficiência energética e da produção de renováveis, e, de acordo com a SEforALL, se disponibilizam à monitoramentos e avaliações para demonstrar a efetividade de suas ações. Já os Proud Partners contribuem de forma mais pontual com a agenda da coalizão. Por fim, os Funding Partners são os parceiros responsáveis pelo orçamento anual do SEforALL e se constituem como Estados, comissões e fundações. Soma-se à essas parcerias, a iniciativa chamada People Centered Accelerator. Lançada em 2017 como uma parceria voluntária, a iniciativa reúne mais de 40 atores que se dizem comprometidos com a promoção da igualdade de gênero, a inclusão social e o empoderamento feminino em busca das metas de energia. Nesse sentido, a multiplicidade de atores parceiros do SEforALL parece reforçar a percepção acerca de um novo modelo de governança, caracterizado por um emaranhado de atores e por mecanismos de implementação menos centrados no Estado.

\section{Figura 3: Parcerias da SEforALL. \\ Elaboração própria com base na análise do documento \\ SEforALL Partnerships Framework.}

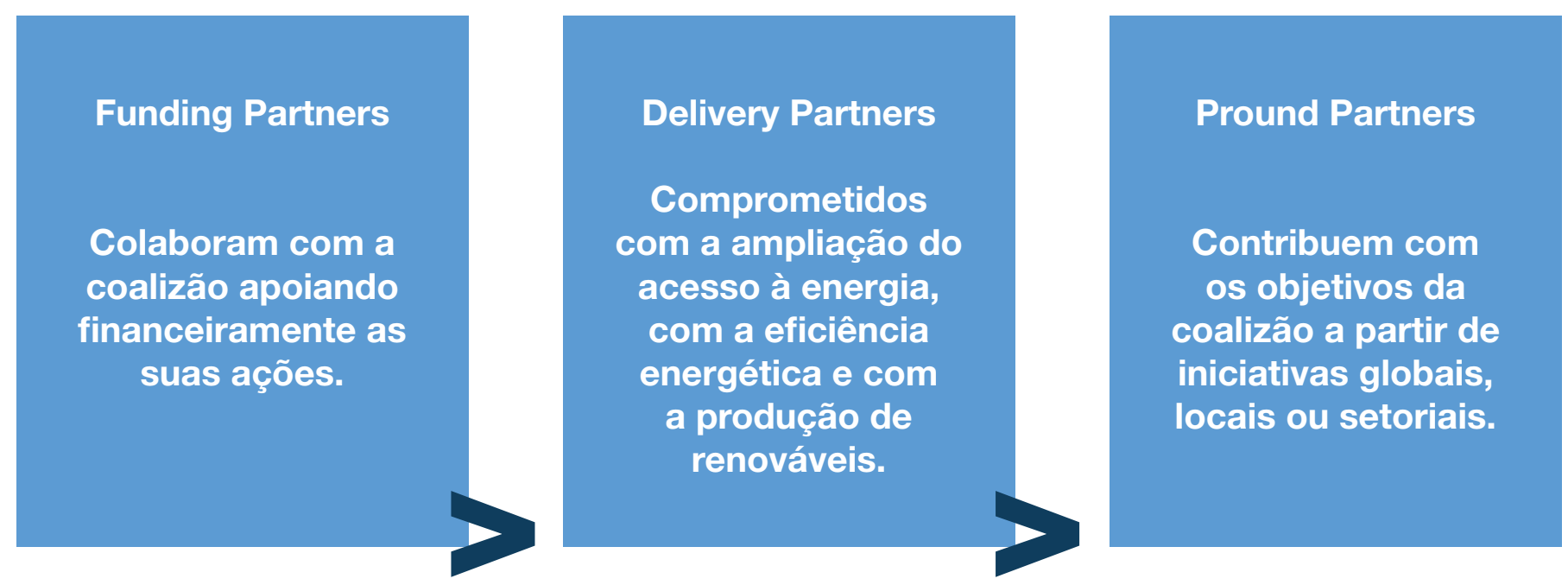

(12) SEforALL 2017 Annual Report. Disponível em: https://www.seforall.org/sites/default/files/SEforALL-2017-AnnualReport.pdf Acesso em: 29 de nov 2018 
Tendo em vista a ampla gama de parceiros e as diferentes categorias empregadas pelo SEforALL, esse PB focará apenas nos Delivery Partners. A escolha por limitar a análise a esse tipo de parceria justifica-se pelo fato de os Delivery Partners se constituírem como atores que se dizem efetivamente comprometidos com o alcance das metas internacionais, o que, teoricamente, implicaria em uma maior aderência aos objetivos do regime de clima.

Apesar de contar com menos membros quando comparado à gama de atores do IRENA, a percentagem de atores privados que compõem os Delivery Partners do SEforALL mostra-se mais alta, alcançando mais de $40 \%$. Entre os interesses ambientais declarados por esses atores, destacam-se a busca pela sustentabilidade na cadeia de produção e consumo, a luta contra as mudanças climáticas, a proteção da biodiversidade e a incorporação de políticas sustentáveis em virtude da crescente pressão dos consumidores. Entre os objetivos sociais declarados são citados: levar energia elétrica sustentável a um maior número de pessoas, desenvolver soluções capazes de dar fim a ciclos de pobreza e exclusão e apoiar o desenvolvimento econômico e social sustentável.

De acordo com o website da coalizão, todos os seus Delivery Partners mostram-se efetivamente comprometidos com o alcance das metas do ODS 7 da Agenda 2030. Contudo, a análise de seus websites e documentos oficiais revelou que, entre as 10 empresas que se configuram como Delivery Partners, 5 demonstram-se discursivamente comprometidas com o ODS $7 \mathrm{e}$ apenas três (Energias de Portugal, Arçelik e Total) citam diretamente o objetivo de contribuir com o alcance das metas do Acordo de Paris, enquanto outra (Schneider Electric) manifesta o desejo de auxiliar outras empresas a contribuir com as metas do acordo.

\section{Quadro 2: Atores Privados de IRENA Coalition for Action e SEforALL e seus interesses ambientais declarados}

\section{SEforAll Delivery Partners}

Total 
Figura 4. Comparação IRENA Coalition for Action e SEforALL. Fonte: elaboração própria.

\section{5}

20

15

10

5

0

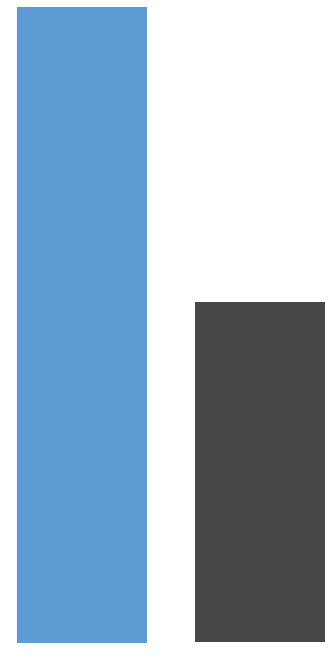

Atores Privados

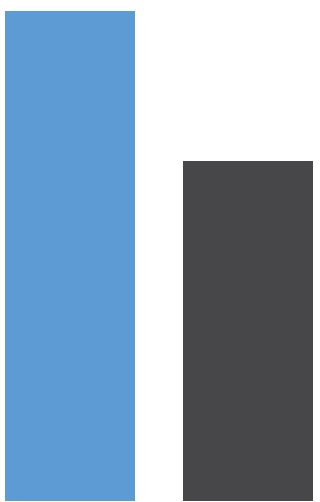

Menções a interesses amibientais

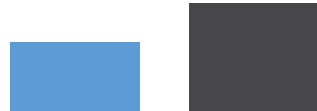

Menções ao Acordo de Paris

Apesar dos discursos oficiais desses atores nem sempre mostrarem aderência aos objetivos do Acordo de Paris, ambas as coalizões mostram-se presentes e participativas meio às COPs. Durante a COP 24, realizada em dezembro de 2018 em Katowice, na Polônia, a Coalition for Action foi responsável pelo lançamento de uma plataforma virtual, chamada Renewables $4 \mathrm{Cli}$ mate, cujo objetivo é disseminar conhecimento acerca do papel das energias renováveis como solução para o problema das mudanças climáticas. A plataforma também disponibilizou informações acerca dos eventos sobre renováveis que aconteceriam ao longo das duas semanas de conferência. Entre os 25 eventos listados no website, 7 foram organizados pelo IRENA, sendo alguns em parceria com outras plataformas, inclusive com o SEforALL.

Se por um lado, a participação destas coalizões em meio às COPs parece apontar para uma preocupação compartilhada em auxiliar no alcance das metas do regime de clima, por outro, a análise dos interesses declarados por esses atores revelou que nem todos se mostram discursivamente comprometidos com os objetivos de redução das emissões. Na próxima seção, será analisado o teor das iniciativas registradas por essas empresas na plataforma NAZCA, bem como os benefícios e deficiências inerentes ao funcionamento de tal plataforma em meio ao regime de governança descentralizada.

\section{Iniciativas na Plataforma NAZCA}

A plataforma NAZCA representa uma tentativa da UNFCCC de mobilizar e contabilizar esforços dos non-party stakeholders - como organizações da sociedade civil, cidades, empresas, regiões e investidores - para combater a mudança do clima. Tal plataforma vem sendo apontada 
por alguns autores como uma evidência do processo de descentralização que estaria em curso em meio à governança do clima. (Bäckstrand; Kuyper, 2015; Jordan et al., 2018)

Atualmente, a NAZCA contabiliza 19.947 iniciativas registradas por 12.396 stakeholders $^{13}$. Entre os 20 membros privados da Coalition for Action, 8 registraram ações, tanto individuais quanto coletivas na NAZCA, que, juntas somam 53 iniciativas. Já entre as 10 empresas privadas que compõem os Delivery Partners do SEforAll, 9 registraram iniciativas na plataforma, totalizando 79 ações, o que parece reforçar o discurso da coalizão acerca do comprometimento de seus membros com as metas do regime de clima.

\section{Quadro 3: Número de Atores e de Iniciativas registradas na Plataforma NAZCA por coalizão}

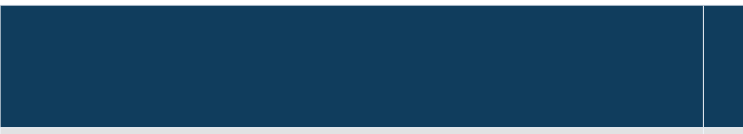

Atores Privados

Atores Privados na NAZCA

Número de Iniciativas na NAZCA
IRENA Coalition For Action

20

8

53
SEforAll

10

9

79

Entre as iniciativas coletivas frequentemente observadas entre os membros das duas coalizões, destacam-se a Put a Price on Carbon - Business Leadership Criteria on Carbon Pricing, que tem como objetivo reunir empresas que utilizam um mecanismo de precificação de carbono com vistas a reduzir emissões; a Low Carbon Technology Partnerships Initiative (LCTPi) e a Science Based Targets Initiative que promove a adoção voluntária de metas de redução de emissões cientificamente comprovadas, de modo a limitar o aumento da temperatura do planeta à menos de $2^{\circ} \mathrm{C}$. Por fim, nota-se também o engajamento de alguns desses atores com a iniciativa coletiva Responsible Corporate Engagement in Climate Policy, que reúne empresas privadas dispostas a influenciar políticas governamentais por meio de suas ações individuais.

A tabela abaixo agrega informações sobre a quantidade de atores privados, membros da Coalition for Action e SEforAll, que participam dessas iniciativas coletivas registradas na NAZCA. Vale notar que essas iniciativas dizem respeito a temas frequentemente discutidos em meio às negociações de clima, o que pode apontar para certa incidência em termos de interesses dos atores privados em meio às negociações. Contudo, novos estudos acerca do tema seriam necessários para determinar de que maneira os interesses dos non-party stakeholders, em especial dos atores privados, vêm influenciando as negociações.

(13) Website Oficial Climate Action UNFCCC. Disponível em: <http://climateaction.unfccc.int/views/map.html> Acesso em: 05 de jan 2019. 


\section{Quadro 4: Atores da IRENA Coalition for Action e do SEforALL que participam de iniciatiavas coletivas registradas na Plataforma NAZCA.}

\begin{tabular}{|l|c|c|c|}
\hline & $\begin{array}{c}\text { IRENA Coalition } \\
\text { for Action }\end{array}$ & SEforALL & Total \\
\hline Put a Price on Carbon & 4 & 5 & 9 \\
\hline Business Solutions to Transition (LCTPi) & 5 & 6 & 11 \\
\hline Science Based Targets & 3 & 7 & 6
\end{tabular}

Já no que diz respeito às iniciativas individuais, verificam-se várias ações registradas por esses atores, que dizem respeito à emissão de green bonds e a fixação de um preço interno para o carbono, bem como o comprometimento com metas voluntárias referentes ao consumo de energias renováveis e à redução de emissões a curto, médio e longo prazo.

\section{Quadro 5: Tipos de Iniciativas coletivas e individuais registradas na Plataforma NAZCA pelos membros das duas coalizões.}

\section{Categorias de Iniciativas Registradas na NAZCA pelos membros da IRENA Coalition for Action e do SEforALL}

\section{Iniciativas Coletivas \\ Estabelecimento de Preços de Carbono}

Engajamento com Políticas Governamentais

Eficiência Energética

Iniciativas Individuais

Energias Renováveis

Emissão de Green Bonds

Redução de Emissões

\section{Descrição}

Grupo de empresas que utilizam um preço interno para o carbono com o objetivo de gerenciar a crise climática

Grupo de empresas que visam influenciar as políticas climáticas governamentais a partir de suas ações individuais

Comprometimento com o uso inteligente de energia

\section{Descrição}

Metas para a produção de energia via fontes renováveis

Emissão de green bonds com o objetivo de investir em projetos de energia renovável

Iniciativas que visam a redução das emissões que podem se voltar ao alcance das metas pré-2020, pós-2020 ou até mesmo não possuir prazos para consecução 
Tendo em vista o entendimento de autores como Ostrom (2010) e da própria UNFCCC de que os non-party stakeholders configuram-se como atores essenciais para garantir o alcance das metas ambientais, iniciativas como a NAZCA costumam ser celebradas como avanços significativos para promover a maior efetividade do regime. Contudo, uma análise mais cuidadosa acerca do funcionamento de tal plataforma revela algumas fragilidades.

Diferentemente do que os autores que defendem os benefícios da governança policêntrica (Ostrom, 2010) afirmam, a NAZCA não oferece mecanismos que garantam que as iniciativas e compromissos registrados pelos non-party stakeholders vão ao encontro das preferências dos indivíduos mais afetados por suas ações. (Bäckstrand; Kuyper, 2015: p. 778) As próprias iniciativas individuais de emissão de green bonds para o financiamento de projetos de energia renovável, como as registradas por alguns dos membros da Coalition for Action e do SEforALL, não apresentam, em sua maioria, quaisquer considerações acerca das consequências desses projetos para as populações locais. (Bäckstrand; Kuyper, 2015: 778) Muitas vezes, iniciativas desse tipo são conduzidos sem quaisquer políticas de salvaguardas socioambientais, podendo, inclusive, ir de encontro aos interesses secundários declarados por essas empresas, como a proteção da biodiversidade, o alívio da pobreza e a garantia de direitos humanos, não garantindo, portanto, a integridade ambiental.

Há também dúvidas sobre até que ponto as iniciativas e metas registradas na NAZCA mostram-se coerentes com os objetivos do Acordo de Paris. De acordo com Bäckstrand e Kuyper (2017: 770), a decisão da UNFCCC de orquestrar as ações dos non-party stakeholders garante o reconhecimento desses atores e legitima suas atividades, o que demandaria uma contribuição mais clara desses para com as NDCs de seus respectivos países e os objetivos do Acordo de Paris. Iniciativas coletivas como a Put a Price on Carbon - que conta com representantes tanto da Coalition For Action quanto da SEforALL - geram intensos debates acerca da efetividade de se estabelecer mecanismos de mercado como soluções para o combate à mudança do clima. As críticas vão desde a dificuldade em se mensurar o volume de emissões reduzido por meio da precificação, passando pelos riscos de contabilização dupla, culminando em argumentos sobre a transferência de responsabilidade sobre os cortes das emissões dos países desenvolvidos para os países em desenvolvimento, de forma a colocar em risco as responsabilidades comuns, porém diferenciadas, um dos princípios basilares da Convenção.

Outro ponto igualmente preocupante diz respeito às questões relacionadas à accountability e à transparência. Tanto a Convenção do clima e seus instrumentos, como as organizações da sociedade civil enfrentam dificuldades para monitorar a atuação dos atores privados, em virtude da carência de informações disponíveis, instrumentos oficiais e voluntários voltados a este fim.

Grande parte das iniciativas individuais registradas pelos membros das duas coalizões na Plataforma NAZCA dizem respeito a metas voluntárias de redução de emissões em médio e em longo prazo (geralmente até 2020 ou 2030) e de utilização de fontes de energia renováveis. O alcance de tais metas voluntárias poderia, em maior ou menor grau, contribuir para a implementação das NDCs das Partes e, consequentemente, para o alcance dos objetivos do Acordo de Paris. No entanto, as dificuldades de monitoramento geram incertezas acerca do gap de implementação e da real contribuição desses atores. Tal constatação se mostra especialmente problemática, à medida que as ações dos non-party estakeholders são reconhecidas como complementares às ações dos Estados e essenciais para o alcance das metas do regime. (Bäckstrand; Kuyper, 2015: 782) 


\section{Considerações Finais}

Estima-se que, até 2050, as energias renováveis e as iniciativas de eficiência energética responderão por cerca de $90 \%$ dos cortes de emissões de gases de efeito estufa necessários para o alcance das metas do Acordo de Paris ${ }^{14}$. Tais números evidenciam, de forma incontestável, a importância do setor de energia para o sucesso do regime do clima. Contudo, as raras menções ao Acordo de Paris nos discursos de atores pertencentes à duas grandes coalizões do setor de energia que se mostram presentes em meio às negociações, bem como o teor de algumas de suas iniciativas registradas na NAZCA sinalizam para um maior interesse em impulsionar o processo de transição energética e não necessariamente contribuir de forma efetiva para o alcance das metas climáticas.

O que se torna preocupante é o fato de que, em meio a essa governança cada vez mais descentralizada, o alcance das metas climáticas esteja crescentemente condicionado às iniciativas dessas empresas, que podem não se mostrar necessariamente comprometidas com o objetivo de limitação da temperatura do planeta, no sentido de auxiliar na promoção de bens públicos globais. Além disso, como os problemas ambientais são globais, o multilateralismo segue sendo fundamental para garantir o comprometimento e o enfrentamento coletivo do problema e a busca por soluções e compromissos universais.

No entanto, não se deve perder de vista os potenciais benefícios inerentes a este modelo de governança descentralizada. Atualmente, nota-se uma tendência preocupante de que grandes potências emissoras como os Estados Unidos se retirem do Acordo de Paris, de modo a colocar em perigo a efetividade do acordo. Mediante este cenário, o comprometimento efetivo dos non-party stakeholders torna-se ainda mais importante, de modo a garantir que, mesmo na ausência dos Estados, atores que se encontram em outros níveis possam tomar medidas que contribuam de forma efetiva com o combate à mudança do clima.

Tendo em vista que a possibilidade de se alcançar as metas climáticas mostra-se altamente dependente das ações dos non-party stakeholders, a UNFCCC poderia elaborar mecanismos ou abordagens de avaliação próprios, capazes de acompanhar de perto a efetividade e o teor das ações registradas na plataforma NAZCA.No mais, visando suprir o deficit democrático e garantir uma maior transparência em seus processos, a criação de canais de comunicação oficiais entre a UNFCCC e as organizações da sociedade civil também se mostra importante. Tais canais facilitariam a denúncia de iniciativas que porventura trouxessem prejuízos socioambientais às comunidades locais, de modo a reforçar a importância de que as ações de combate à mudança do clima ocorram em consonância com a proteção de direitos.

Reconhecendo, assim, a importância da contribuição dos non-party stakeholders para com as metas do regime do clima, o que se busca, a partir desta análise, não é descredenciar o modelo de governança policêntrica, mas, com base na identificação de suas deficiências, apontar para caminhos que possam levar ao seu aprimoramento. Dessa forma, é importante continuar testando a Governança Policêntrica como matriz analítica do regime de clima e aprofundar as análises acerca de como esse modelo de governança poderia ser aperfeiçoado, no sentido de garantir transparência, representatividade e comprometimento dos atores para com o alcance das metas do regime. 


\section{Referências Bibliográficas}

Abbott, K. W; Snidal, D. International regulation without international government: Improving IO performance through orchestration. The Review of International Organizations, 5(3), 2010 315-344.

Bäckstrand, Karin; Khan, J.; Kronsell, A; Lövbrand, Eva. Environmental Politics and Deliberative Democracy. Cheltenham: Edward Elgar, 2010.

Bäckstrand, Karin; Kuyper, Jonathan W. The democratic legitimacy of orchestration: the UNFCCC, non-state actors, and transnational climate governance, Environmental Politics, 26:4, 2017, p. 764-788.

Bäckstrand, Karin; Kuyper, Jonathan W, Linnér, Björn-Ola, Lövebrand, Eva. Non-state actors in global climate governance: from Copenhagen to Paris and beyond. Environmental Politics, v. 26, n. 4,2017 , p. $561-579$.

Benner, Thorsten; Ivanova, Maria; Streck, Charlotte; Witte, Jan Martin. Moving the Partnership Agenda to the Next Stage: Key Challenges. In: Benner, Thorsten; Streck, Charlotte; Witte, Jan Martin. Progress or Peril? The Post-Johannesburg Agenda. Global Public Policy Institute, 2003.

Biermann, Frank; Chan, Man-san; Aysem, Mert; Pattberg; Philipp. Multi-stakeholder Partnerships for Sustainable Development: Does the promise hold? CSR Paper, 28.2007. Disponível em: <http://www.feem.it/Feem/Pub/Publications/CSRPapers/default.htm> Acesso em: 20 de set 2018.

Galvanizing the Groundswell of Climate Actions. Lima-Paris Action Agenda Independent Assessment report, 2015. Disponível em: <https://static1.squarespace.com/static/552be32ce4b0b269a4e2ef58/t/56673b3cb204d59deb517d8d/1449605948836/LPAA Assessment Report 7DEC15.pdf> Acesso em: 25 de jan 2019.

Global Climate Action. Disponível em: <http://climateaction.unfccc.int/> Acesso em: 24 de jan 2019.

Inoue, Cristina Yume Aoki. Governança global do clima: proposta de um marco analítico em construção. Rev. Carta Inter., Belo Horizonte, v. 11, n. 1, 2016, p. 91-117.

IRENA Coalition for Action. Disponível em: <http://coalition.irena.org/-/media/Files/IRENA/ Coalition-for-Action/IRENA-Coalition-for-Action June-2018 v1.pdf> Acesso em: 04 de jan 2019.

IRENA Coalition for Action. Working Together to drive the global energy transition, 2018. Disponível em: <https://coalition.irena.org/-/media/Files/IRENA/Coalition-for-Action/IRENA-Coalition-for-Action June-2018 v1.pdf> Acesso em: 08 mai 2019.

Jordan, A., et al. Emergence of polycentric climate governance and its future prospects. Nature Climate Change, 5, 2015, p. 977-982.

Jordan, A., et al. Governing Climate Change: Polycentricity in Action? Cambridge, Nova Yorl, Melbourne, Nova Delhi: Cambridge University Press, 2018 
Mert, Aysem. Hybrid governance mechanisms as political instruments: The case of sustainability partnerships," International Environmental Agreements, 14 (3): 225-244, 2013.

Mert, Aysem. Institutions in global environmental politics: Public-private partnerships, in Zelli, F; Pattberg, p (Eds.) Edward Elgar Encyclopaedia of Global Environmental Politics and Governance, pp. 291-295.2015

Ostrom, Elinor. A Polycentric Approach for Coping with Climate Change, Policy Research Working Paper 5095, 2010.

Renewables 4 Climate. Disponível em: <http://www.renewables4climate.org/> Acesso em 20 dez 2018.

SEforALL. Partnerships Framework, 2016. Disponível em: <https://www.seforall.org/sites/ default/files/2019-04/SEforALL Partnerships Framework Document.pdf> acesso em: 08 mai 2019.

SEforALL. SEforALL 2017 Annual Report. Disponível em: <https://www.seforall.org/sites/default/files/SEforALL-2017-Annual-Report.pdf> Acesso em: 29 de nov 2018

Streck, Charlotte. New Partnerships in Global Environmental Policy: the Clean Development Mechanism, The Journal of Environment and Development, 13 (3), 2004, p. 295-322.

Victor, D.G. Global Warming gridlock: creating more effective strategies for protecting the planet. Cambridge: Cambridge University Press, 2011.

\section{Lista de Documentos e Websites Consultados}

Abengoa Website Oficial. Disponível em: < http://www.abengoa.com/export/sites/abengoa corp/resources/pdf/gestion responsable/politica-ambiental.pdf > Acesso em: 08 de mai 2019.

Abengoa Website Oficial. Disponível em: http://www.abengoa.com/web/es/gestion responsable/nuestro compromiso/medioambiente y cambio climatico/politica-ambiental/ Acesso em: 10 jan 2019.

ACCIONA Website Oficial. Disponível em: https://www.acciona.com/sustainability/enviroment/ Acesso em: 10 jan 2019.

ABB Website Oficial. Disponível em: < https://new.abb.com/sustainability/environment e https://new.abb.com/sustainability/environment/energy-and-climate > Acesso em: 20 fev 2019.

Access Power Website Oficial. Disponível em: <http://www.access-power.com/about-us https://bester.energy/inventario-de-emisiones/> Acesso em: 10 fev 2019.

Arçelik Website Oficial. Disponível em: http://www.arcelikas.com/page/210/Climate\%20 Change Acesso em: 05 mai de 2019.

Azelio Website Oficial. Disponível em: https://www.azelio.com/about-us/this-is-azelio/ Aces- 
so em: 30 jan de 2019.

Danfoss Website Oficial. Disponível em: https://www.danfoss.com/pt-br/about-danfoss/insights-for-tomorrow/energy-and-water/ Acesso em: 05 mai de 2019.

Enel Website Oficial. Disponível em: https://www.enel.com/aboutus/vision Acesso em: 05 mai de 2019.

Energias de Portugal Website Oficial. Disponível em: https://www.edp.com/en/edp/what-we-do/energy Acesso em: 05 mai de 2019.

First solar website Oficial. Disponível em: http://www.firstsolar.com/About-Us/Corporate-Responsibility Acesso em: 08 mai de 2019.

Iberdrola Website Oficial. Disponível em: < https://www.iberdrola.com/conocenos/energetica-del-futuro/nuestros-compromisos> Acesso em: 05 mai de 2019.

Johnson Controls Website Oficial. Disponível em: https://www.johnsoncontrols.com/corporate-sustainability/environment Acesso em: 05 mai de 2019.

Mainstream Website Oficial. Disponível em: https://www.mainstreamrp.com/about-us/our-company/sustainability/ Acesso em: 20 fev de 2019.

Masdar Website Oficial. Disponível em: https://masdar.ae/en/about-us/management/vision-mission-and-values Acesso em: 15 jan de 2019.

Novozymes Website Oficial. Disponível em: https://www.novozymes.com/pt/about-us/sustainability Acesso em: 20 fev de 2019.

Qway Website Oficial. Disponível em: http://qway.energy/ Acesso em: 05 mai de 2019.

Revelle Website Oficial. Disponível em: http://www.revellegroup.com/values/ Acesso em: 03 mar de 2019.

Schneider Eletric Website Oficial. Disponível em: https://www.schneider-electric.us/en/ about-us/sustainability/climate-change/ Acesso em: 07 mai de 2019.

Signify Website Oficial. Disponível em: https://www.signify.com/pt-br/sustainability Acesso em: 07 mai de 2019.

Skypower Website Oficial. Disponível em: https://skypower.com/a-social-responsibility/ Acesso em: 08 mai de 2019.

Sunlabob Website Oficial. Disponível em: http://www.sunlabob.com/about-us.html\#corporate-responsibility Acesso em: 08 mai de 2019.

Total Website Oficial. Disponível em: https://www.total.com/en/commitment/environmental-issues-challenges/climate-change Acesso em: 07 mai de 2019.

Vestas Website Oficial. Disponível em: https://www.vestas.com/en/about/sustainability\#!commitments Acesso em: 08 mai de 2019. 


\title{
Anexo 1: Lista de Atores Privados Membros da IRENA Coalition for Action
}

\author{
Abengoa Solar \\ ACCIONA \\ $\mathrm{ABB}$ \\ Access Power \\ Bester \\ Cleanergy (Azelio) \\ Enel Green Power \\ First Solar \\ FTI Consulting \\ Iberdrola SA \\ Mainstream Renewable Power \\ MAKE \\ Masdar Clean energy \\ Novozymes \\ Planet Energy Now \\ Qway Energy \\ Revelle Group \\ Skypower \\ Sunlabob Renewable Energy \\ Vestas Wind System
}

\section{Anexo 2: Lista de Delivery partners privados do SEforALL}

ABB

Arçelik A.S

Danfoss

ENEL

Energias de Portugal

Iberdrola

Johnson Controls

Signify

Scheneider Electric

Total 


\section{Sobre a autora}

Beatriz Rodrigues Bessa Mattos é doutoranda em Relações Internacionais pelo Instituto de Relações Internacionais da Pontifícia Universidade Católica do Rio de Janeiro (IRI/PUC-Rio). Pesquisadora da Plataforma Socioambiental do BRICS Policy Center. Foi Pesquisadora Visitante do Programa Mistra Geopolitics, pelo Departamento de Ciência Política da Universidade de Estocolmo e pelo Departamento de Estudos Temáticos da Universidade de Linköping (TEMA/ LiU). Professora Assistente da Universidade Veiga de Almeida. Possui como principais interesses de pesquisa temas relacionados ao meio ambiente e estudos críticos de segurança.

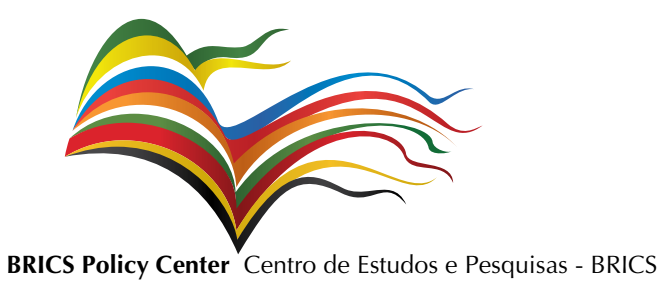

Rua Dona Mariana, 63 - Botafogo - Rio de Janeiro / RJ - Brazil

Phone: (+55 21) 2535-0447 / ZIP CODE: 22280-020

www.bricspolicycenter.org / bpc@bricspolicycenter.org 